\section{Understanding Chinese consumers' safety perceptions of dairy products: a qualitative study}

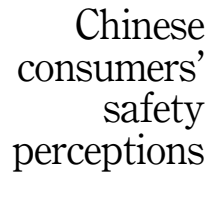

1837

\author{
Department of Agricultural and Food Sciences,
} Alma Mater Studiorum-University of Bologna, Bologna, Italy and Department of Economic and Trade, Xinjiang Agricultural University, Ürümqi, People's Republic of China, and Maurizio Canavari Department of Agricultural and Food Sciences, Alma Mater Studiorum-University of Bologna, Bologna, Italy

Received 10 April 2019

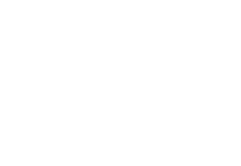

\begin{abstract}
Purpose - Dairy products are an essential part of a healthy diet, and dairy is an emerging food industry in China. Meanwhile, the dairy industry is one of the "disaster zones" with quality and safety issues occurring more frequently in its supply chain than in others. Based on qualitative research focused on consumers in the Northwest and South of China, the present study aims to understand and provide information on consumer perception of food safety in dairy products.

Design/methodology/approach - Nine focus group interviews were carried out from January to April 2018. Altogether, 61 participants (24 males, 37 females, aged 18-60 years) were recruited in four cities. Qualitative content analysis of the data was conducted using Nvivo version 11.4.0.

Findings - A high concern with the safety of dairy products is widespread, particularly among participants with children, who are especially worried about the safety of dairy products. High prevalence of food safety incidents causes consumers to lower their confidence in food safety, and make them pay more attention to the news about food safety incidents. Consumers tend to become less sensitive to price, focusing more on food safety and quality, while purchasing dairy products. Brand and purchase venue are the most important indicators for consumers to determine the quality of dairy products. Safety certification becomes increasingly important.

Research limitations/implications - It has some limitations. The focus group interviews covered different two regions (Northwest and South of China). However, the number of focus groups was limited to nine because of budget constraints. The participants come from Northwest and South of the country, which means that the findings may not apply for another area of the country. A more representative sampling with a larger sample size would be necessary to increase the validity of the study. However, the results can serve as input for further research.

Originality/value - This paper explores the Chinese consumers' perception of food safety and dairy products, consumers' behaviour concerning dairy products based on focus group interviews with consumers. This study offers valuable insights to members of academia, food suppliers and policy-makers.
\end{abstract}

Keywords Focus group, Consumer, Perception, Dairy products, Food safety

Paper type Research paper

(C) Shalamujiang Maitiniyazi and Maurizio Canavari. Published by Emerald Publishing Limited. This article is published under the Creative Commons Attribution (CC BY 4.0) licence. Anyone may reproduce, distribute, translate and create derivative works of this article (for both commercial and noncommercial purposes), subject to full attribution to the original publication and authors. The full terms of this licence may be seen at http://creativecommons.org/licences/by/4.0/legalcode

The authors thank the individuals who participated in the focus groups for openly sharing their thoughts and experiences. Also, we appreciate the time committed by MengXi Qiao, Master's degree candidate at the Alma Mater Studiorum-University of Bologna, in analysing the qualitative data. This research was performed in the framework of the $\mathrm{PhD}$ project of the first author. This work was financially supported by the Xinjiang Autonomous Region Humanities and Social Sciences Arid Area Rural Development Research Center Bidding Project (XJEDU030115C03).

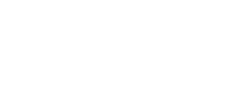


BFJ

123,5

1838

\section{Introduction}

Chinese consumers regard current food safety problems as very serious, primarily due to the frequent occurrence of food safety incidents in China in recent years. Repeated outbreaks of various food safety incidents in China hurt public confidence in domestic food (Wu et al., 2013), resulting in many consumers pay growing attention to the safety and quality of dairy products. In order to enhance consumer confidence in food safety, the Chinese government has undertaken various policy measures to improve the safety and quality of food. However, consumers have not enough confidence in the safety of dairy products. Most scholars who have analysed food safety perception for different food categories in China have concluded that a high level of consumer concern exists about food safety and quality. A survey conducted in 2009 showed that respondents were very much concerned $(41.8 \%)$ or relatively concerned (42.2\%) about food safety (Liu et al., 2009). Food safety was ranked first in the top five safety issues that worried the Chinese consumer, surpassing public safety, traffic safety, health safety and environmental safety (Lam et al., 2013). A study conducted in Weifang, Shandong Province, showed that $97.3 \%$ of interviewees showed attention for food safety (Bu et al., 2013). Liu et al. (2014) reported that respondents were most worried about counterfeit and inferior quality food, probably because Chinese consumers have been frequently confronted with such issues. A structured survey on consumers' food safety risk perception showed that the mean score of consumers' risk perception for food safety on a 1-7 scale is 5.234, thereby indicating that consumers generally have high-risk perceptions (Yin et al., 2017).

Many studies have shown that people with different socio-demographic characteristics (gender, age, income, education and the number of children in the household) differ in food safety perceptions, preference and purchase behaviour. Consumers were mainly concerned with pesticides residues, additives, preservatives and sale of food beyond its expiration date. Food scares have taken place in China over the last decades are numerous, but one of the most emblematic is the 2008 China melamine milk incident, which has dramatically increased Chinese consumers concerns about food safety and food quality and put the dairy industry in the spotlight for food safety issues (Qiao et al., 2010; Wu et al., 2018; Zhang et al., 2010).

Dairy products are an essential part of a healthy diet, and dairy is an emerging food industry in China. According to the China National Bureau of Statistics, from January to May 2018, the output of dairy products was 10.06 million tons with year-on-year growth of 7.6 per cent and sales in the first quarter of 2018 totalled 585.73 million tons. However, the per capita milk consumption in China is much lower than in many other countries. China's per capita milk consumption is about $36 \mathrm{~kg} /$ person, which is less than $1 / 3$ of the world average and less than $1 / 10$ when compared to developed countries (Ward and Inouye, 2018). With the rapid economic development and growth in the income of residents, Chinese consumers are increasingly healthconscious and are becoming more selective about the quality and safety of dairy products they consume. Therefore, there is room for substantial growth of high-quality dairy product consumption in China (Guozheng et al., 2012; Qiao et al., 2012; Ward and Inouye, 2018).

Meanwhile, the dairy industry is one of the "disaster zones" with quality and safety issues occurring more frequently in its supply chain than in others ( $\mathrm{Zhu}$ and $\mathrm{Xu}, 2017)$. Government and media reports on dairy-related food safety incidents in China between 2004 and 2017 total to 233 (Zhu et al., 2019). Although after the melamine milk scandal of 2008, China's government reformed the management of dairy products and associated laws to strengthen food safety regulations and raise technical standards to improve the safety of dairy products (Zeng et al., 2018), consumers' trust on food safety of dairy products remains low.

Xinjiang is the shortened form for Xinjiang Uygur Autonomous Region which is situated in Northwest China. It is one of the most important high-quality milk source and production area of dairy products in China, the consumers living there may be considered more familiar with the production and processing of dairy products than whose living in the South of China. Familiarity may change consumers' risk perception, lowering concern about possible adverse 
effects of the products, and reducing consumer scepticism (Verbeke et al., 2009). Consumers' familiarity and expertise with a product category are considered key moderators of the role played by extrinsic cues in the choice utility function (Chocarro et al., 2009).

Quality and safety are two important elements in consumer food perceptions and decision making associated with food choice (Feng et al., 2012). Furthermore, they have a great significance for the marketing activities of dairy enterprises. Hence, understanding consumer perception and preference of dairy products provide critical information for firms working in the food supply chain business to develop marketing strategies.

Although some descriptive, quantitative studies assessed consumer perceptions of dairy products safety in China, there is a lack of qualitative research in this field. Qualitative research has the advantage of avoiding constraining respondents into a pre-determined framework for respondent's answers, thus giving the respondent the possibility to express his/her thoughts more freely. The risk of relying only on quantitative research is that the responses may reflect the researcher's way of thinking rather than the consumers' one. So far, little qualitative researches examined Chinese consumers' attitudes and perception of safety with dairy products and with this research, we aim to fill this research gap.

This paper addresses the following objectives:

(1) to explore Chinese consumers' attitudes, preference and behaviour regarding dairy products

(2) to explore Chinese consumers' perceptions of food safety for dairy products, considering both consumers who are familiar with dairy products and consumers who are not

The remainder of the paper is organised as follows: the focus group method applied is illustrated, the data are analysed and discussed, then conclusions are drawn.

\section{Materials and methods}

Many methods are available for eliciting perception associations from consumers, ranging from qualitative techniques, such as individual in-depth interviews and focus groups, to quantitative methods (Hasimu et al., 2017). We decided to use focus group interviews with consumers, performing an initial exploration of consumer perception regarding dairy products.

Focus group data were collected and analysed mainly for market researchers to assess consumers' attitudes and opinions (Onwuegbuzie et al., 2009). The purpose of using focus groups is to gather information about the topic of interest from a relatively small group of people. A focus group study design was chosen to take advantage of group dynamics (i.e. interactions between participants) which allows for a better observation of consensus and disagreements between individuals (Belk et al., 2013). Group discussions may facilitate greater disclosure by participants through reciprocity, i.e., disclosure by one participant may prompt greater disclosure by others (Kum et al., 2018). Focus group outcomes obviously rely on much smaller sample sizes compared to those used with quantitative research methods, and the results obtained, although valid and comprehensive, are typical to be considered exploratory (Mirosa et al. 2020). The focus group method has been used in the study of consumers perception in the food markets in China or other countries (Asioli et al., 2014; Bruschi et al., 2015; Cui et al., 2016; Kendall et al., 2018; Lindberg et al., 2018; Roos et al., 2016; Williams et al., 2005).

\subsection{Procedure}

The interview schedule and guideline were prepared based on the literature review based on quantitative papers, but with the intent to explore whether additional aspects and issues 
$\mathrm{BFJ}$

123,5

1840

could emerge from the focus group discussions. Since we adopted an exploratory approach, the attempt was to avoid to be affected by the existing studies, privileging the voice of the consumers. The focus group discussion was split into three sections. In the first section, participants were asked to give their opinion relating to food safety concerns. In the second section, consumers were asked about the purchasing behaviour of dairy products. The last section led the group into discussions about food safety perception of dairy products, with a focus on consumer attitudes and perception of food safety for dairy products.

Following a welcome introduction, the discussion opened with questions relating to the purchasing behaviour of dairy products. Afterwards, in order to understand consumers perception of food safety in the dairy sector, we asked participants to talk about their perspective of food safety situation in the dairy sector, and which aspect their concerns about dairy products. Participants were also asked to talk about their personal or relatives' experience with food safety issues and the influence of news reports on their concerns about food safety in the dairy sector. The full discussion guide is available from the authors on request.

Each focus group interview lasted approximately 90 minutes; before starting the interview, participants were provided with the interview guide. The participants were told to discuss three categories of dairy products: (1) Milk, (2) Yogurt, (3) Milk powder.

To take into account a possible difference in attitudes and perceptions of safety for dairy products among consumers living in producing and non-producing areas in China, we recruited the participants in the Northwest (producing area) and the South of China (non-producing area).

Nine focus group interviews with a total of 61 consumers were conducted in four Chinese cities. Geographically, data were collected in Urumqi and Changji (Northwest Group), and Haikou and Quanzhou (South Group) (Figure 1). Urumqi and Changji belong to the Xinjiang Uygur Autonomous Region (Xinjiang). Urumqi is the capital city of Xinjiang. Haikou is the capital, and most populous city of the Hainan province and Quanzhou is the largest metropolitan region in the Fujian province, its GDP ranked first in the Fujian Province for 20 years from 1991 to 2010. To a certain extent, the Haikou and Quanzhou are representative of the coastal regions of South China.

The Focus groups were conducted from January to April 2018. Altogether, 61 dairy consumers (24 males, 37 females) participated in the focus group interviews. Three focus group sessions were held in Changii, and two focus group sessions were held in the other three locations.

Figure 1.

Focus group locations

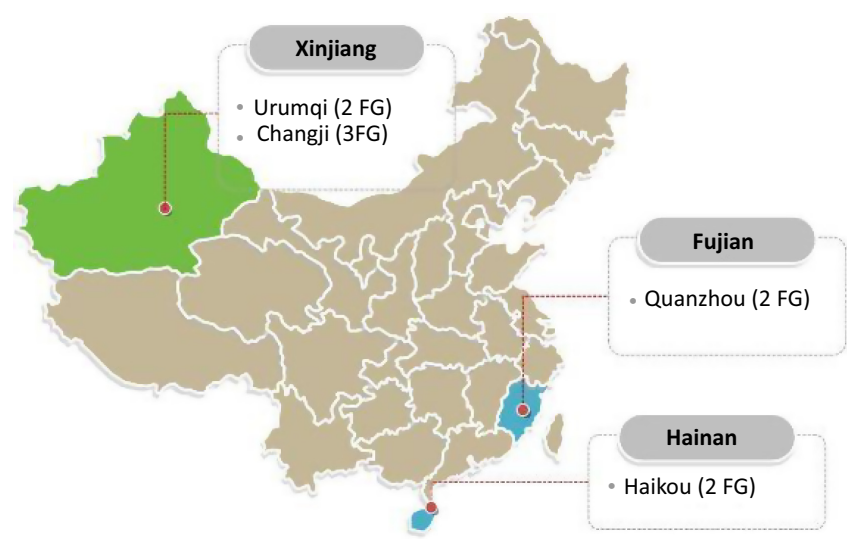


A group size of six to twelve people is generally recommended since if there are more than 12 , the session takes too long, and group interaction becomes more difficult to achieve, if there are fewer than six, there may be insufficient interaction (Lichtman, 2014). Consistently with best practice, in our study each focus group contained 6-9 participants recruited based on selection criteria aimed of achieving a balance for demographic characteristics and purchasing habits, specifically: (1) gender (40\% males and 60\% females), (2) age (18-60 years), (3) education background, (4) socio-economic status (middle/upper class) and (5) purchase of dairy products in the last three months. The final composition of the groups is summarised in Table 1.

A total of five themes were discussed in focus group discussion: Consumers' food safety perception; Consumers' concern about dairy products; Influence of social media on consumers' perception; Consumers' concerns while purchasing dairy products; how do consumers determine the safety of dairy products.

\subsection{Data analysis}

The participants' agreement to take part in the focus groups was based on fully informed consent; all participants are anonymised. All of the focus group discussions were recorded and transcribed verbatim by two research assistants managing the interviews and checked by the first author to ensure consistency. Data input and analysis were carried out using the software Nvivo version 11.4.0 for Windows, which has features such as character-based coding, rich text capabilities and multimedia functions that are crucial for qualitative data management (Zamawe, 2015). The first author read and re-read the verbatim text and then carried out the open coding. Next, the text chunks were categorised based on the research questions, identifying the main semantic category headers.

\section{Results}

\subsection{Consumers' food safety perception}

The first of this study's objectives is to understand the Chinese consumers' perception toward the safety of dairy products. Within the focus groups, most of the participants expressed more concern about food safety. When asked about the safety of dairy products, the majority of participants reported that they were "worried" or "very worried" about the safety of dairy products, thus confirming that food safety is a widespread concern.

However, the results from the discussion show that consumers who live in different areas have a different perception of food safety in the dairy industry. As expected, participants in the Northwest group, although concerned about food safety issues, they are sensibly more optimistic about food safety than participants in the South group. The main reason for that could be the region in which they live - Xinjiang is one of the five traditional pasturing areas and one of the most important milk source base of China. Participants in the Northwest group consistently expressed more confidence about the food safety of dairy products, mainly because they feel assured by the local origin of the product and the reputation of the area as specialised in livestock farming.

Those participants who have older people or children (under 16 years old) in their household, seemed to express more concern about food safety and quality in the dairy sector: since they prepare food for their children or parents, they pay more attention to food safety.

\subsection{The aspects of consumers' concern about dairy products}

When asked which aspect of food safety do concern on dairy products, "chemical residues", "food additives" and "microbial pathogens" are the words at the forefront of the discussion. Chemical residues were mentioned by more than half of the participants; next, food additives 
BFJ

123,5

1842

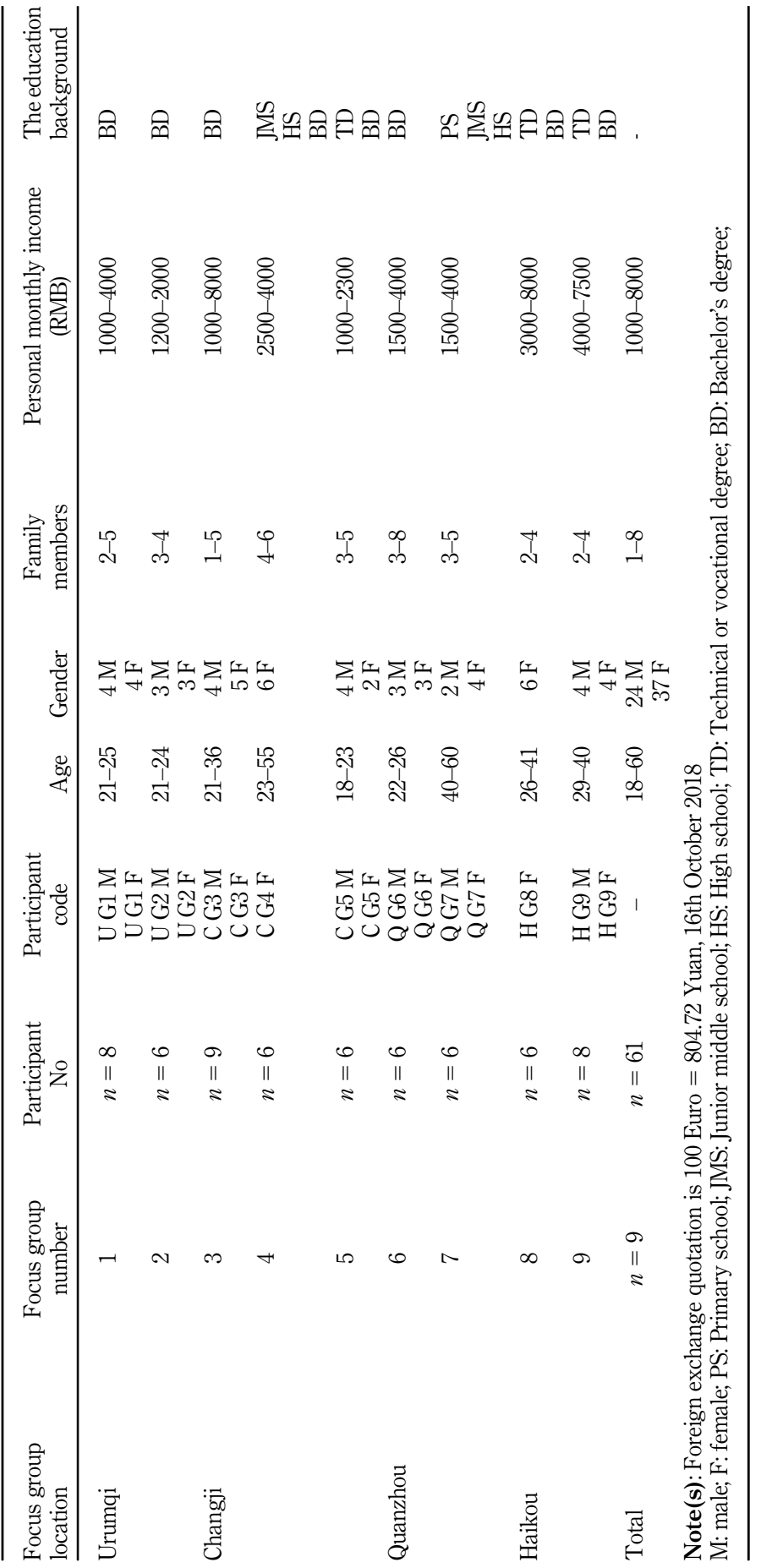

Table 1.

Focus group participants' characteristics 
and microbial pathogens follow. This reveals that there could be a misperception of the most frequent sources of concern. In fact, according to reports from media and survey data, the number of food safety incidents caused by the chemical contamination is less than those caused by microbial agents, by the toxic animal or plant foods. For example, in 2012, 6685 incidents were reported by mass media, most of them attributable to microbial agents (56.1\%), followed by toxic animal or plant foods (14.8\%), and chemical contamination $(5.9 \%)$ (Lam et al., 2013). Some other participants declared that they also worry about expired food and heavy metal pollution.

\subsection{The influence of social media on consumers' perception}

The probable reason why people are more worried about chemical residues is that the food-safety scandals had occurred before. Media coverage plays an important role in people's food-risk perceptions following a major food scare, as media perspectives on the safety of the food supply might have an impact on those of the general public (Zingg et al., 2013). Participants gave many examples of cases of food safety incidents that had been reported in the media, such as the Sudan red and the Melamine milk scandal. Personal or friends' experience in food safety is another major factor affecting consumers' perception. Fifteen participants out of 61 , replied that they or their friends and relatives had a negative food safety experience.

\section{Purchasing behaviour}

\subsection{Consumers' concerns while purchasing dairy products}

When asked to the factors that concern the participants while purchase dairy products, we surprisingly found that, overall, the most mentioned word was "freshness". Safety and quality tied for second, followed by dairy company brand and price, while consumers did not very much mention nutrition. We compared the consumers' concerns among two groups according to their geographical location. Some representative quotations highlighting possible differences in the attitudes are presented in Table A1 in the Appendix. The answers collected from the discussion are graphically depicted in Figure 2 using word clouds. It is a visual representation of text data, widespread for reporting qualitative data (Cappelli et al., 2017). The most frequent words appeared to represent the key concerns of consumers while purchasing dairy products, as it has demonstrated from the word cloud. The results showed that the "freshness" was more mentioned in the Northwest groups"(groups 1-5) than in the

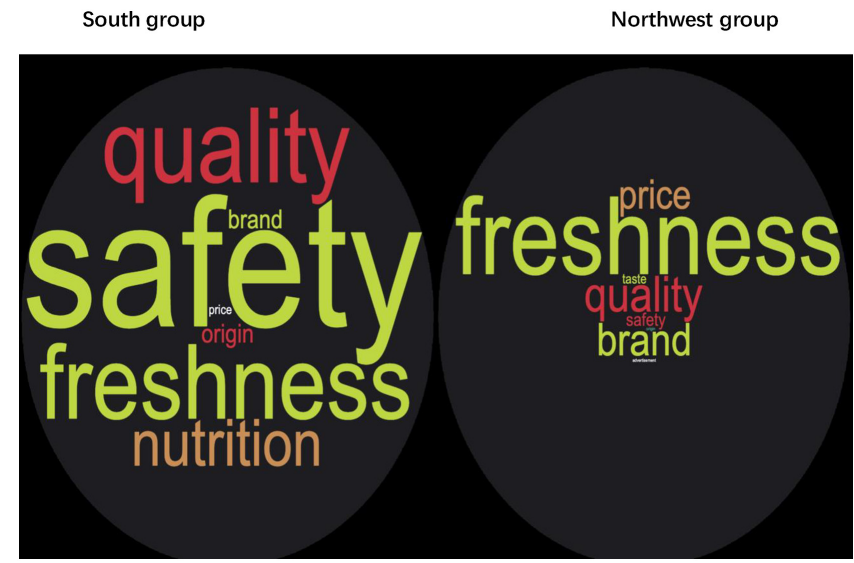

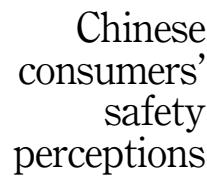

1843 
BFJ

123,5

1844

South groups (groups 6-9). However, the participants in the South groups are more concerned about "safety" or "quality" as compared with the previous groups. Participants living in the Northwest of China reported that they would prefer to select the fresher ones while purchasing dairy products; they believe the freshness is closely associated with related safety. This association is not particularly new, but it is interesting that it is more frequent among respondents form the producing area.

Brand of the dairy company is another factor that consumers consider when they buy dairy products; they use the brand name when evaluating the quality of dairy products. A milk firm's reputation as represented by its brand is also heavily relied upon in searching for safer products (Zhang et al., 2010).

\subsection{How do consumers determine the safety of dairy products?}

We aimed to learn about how consumers determine the safety of dairy products. Discussion among the participants revealed the importance attached by consumers to brand during their purchase decision process. The brand name was used as a cue to judge the prestige of the products, and it represents an extrinsic attribute consumers use to assess product quality (Boncinelli et al., 2019; Brucks et al., 2000). Since consumers believe that food companies should comply with laws that are in place, as well as secure food the quality and safety to protect consumer health, a well-known brand means a food safety guarantee for people, and it is particularly important for consumers who lack complete information related to food safety.

When asked about their preference for dairy company brands, respondents who are from the Northwest groups, overwhelmingly chose the local brand. Apparently, they have confidence in those local dairy company brands, and among them, some dairy enterprises were members of a school milk program, so they are responsible for providing liquid milk to schools. On the contrary, the respondents from the South of China chose the national brand over the local brand.

The results from discussion show that another important safety indicator for consumers is the purchase venue. Obviously, in search of safer dairy products, participants from both groups (Northwest and South) showed more trust in the supermarket; although, some of the participants who in North group also expressed trust in a convenience store, the supermarket is generally the first choice to purchase dairy products. Consumers tended to use brand names and purchase venue to determine milk safety (Zhang et al., 2010), purchasing at the supermarket is perceived to be safer, probably because consumers believe quality requirements and controls by the authorities are the strictest.

The focus groups also revealed that some of the respondents prefer to trust safety certification, instead of brand or supermarket. They were more likely to trust the products certified by the Government, followed by third-party certified or international certificated. What caught our attention is that more than half of participants who trust the certification are highly educated.

\section{Discussion}

The present study described the perception of food safety and purchasing behaviour related to dairy products, considering dairy consumers living in the Northwest and the South of China. The results highlighted that food safety consistently ranks among the top concerns of participants in the discussion. The outcome of this discussion is not surprising given that Chinese consumers are, in general, gravely concerned about the quality and safety of their food. On this respect, our study confirms findings in the previous literature (Chen et al., 2013; Qiao et al., 2010; Veeck et al., 2015; Zhang et al., 2010). However, it is worth noting that, although participants living in the Northwest of China are also worried about food safety issues, they appear to have more confidence in the food safety of dairy products compared to 
participants living in the South of China. This result does not align with other qualitative studies which reported that regardless of familiarity level, consumers' risk perception is similar (Borgogno et al., 2015). The main reason for this higher confidence is maybe because Xinjiang is one of the most important high-quality milk sources and significant production areas of dairy products in China.

The participants with children or older people showed more concern about food safety in the dairy sector. Our findings are in line with the previous study that found that the respondents who had children more concern about milk safety (Gao et al., 2015).

A previous study indicated that counterfeit (tainted) food is the most important safety threat for consumers, while other major concerns among the Chinese respondents, such as chemical contamination and pollution, ranked second and third (Veeck et al., 2015). Our results show that regarding the consumption of dairy products chemical residues are still the biggest concern for most consumers. Probably this is because China ranks among the highest users of fertilisers and pesticides (Jin et al., 2017). Consumers pay attention to the reports related to food safety incidents in the media that recently also include social media such as blogs, microblogs and WeChat. This is consistent with a previous study, which shows that consumers could easily notice food-safety scandals revealed by media, further affecting their judgments of expected utility and their purchasing behaviour (Peng et al., 2015).

Another factor highlighted in the focus group discussion is that direct or indirect personal experience with food safety issues would affect consumers' confidence in food safety, as also confirmed by the previous literature (Hansstein, 2015).

Discussions among the participants revealed that food risks are generally associated with specific attributes of food such as freshness and local provenance. Several respondents believe that freshness is associated with closely related safety while shopping for dairy products. This is peculiar for the Chinese culture since consumers are not used to consuming matured cheese and look for fresh milk, soft cheese, and yoghurt, etc. Particularly, the participants who live in the dairy-producing region trust more the local brand; they prefer to choose fresher while shopping. Freshness has to be seen as the main cue for them in determining the safety of dairy products. This is probably because some of the dairy products such as fluid milk, yoghurt and ice cream will spoil quickly like other fresh foods, which are most common in the Chinese food market. Instead, when dealing with the milk powder freshness is not considered because it is a heavily processed dairy product. This finding is in line with previous studies that accounted freshness as one of the essential affecting factors on consumers' fresh food purchase (Chamhuri and Batt, 2015; Cheng et al., 2016; Feng et al., 2012; Wang and Huo, 2016). To the authors' knowledge, however, no previous studies on Chinese consumers' perception dairy products safety had discussed "freshness" as a cue for safety.

The literature shows that Chinese consumers have a reputation for highly price-sensitive in food purchase decisions (Wang et al., 2008). However, our result goes beyond previous findings, showing that food safety, quality and brand of dairy products are generally considered more important than price. With improved living standards, consumers tend to become less sensitive to price, and the trend is even more apparent among young Chinese consumers. This finding is consistent with the findings of $\mathrm{Xu}$ et al. (2010) that, though previously perceived to be relatively more price sensitive compared to other Asian consumers, younger generations of Chinese consumers have shown being willing to pay a modest premium for certified safe milk products.

The Brand, purchase venue, and certification are the most important indicators for consumers to determine the quality of dairy products. The participants living in the dairyproducing province strongly emphasised their preference for the local brand. This confidence may come from a previous positive experience with the dairy products and familiarity with the brand. The literature has found that positive previous experience and familiarity with products may boost the evaluation of consumers (Verbeke et al., 2009). 
BFJ

123,5

The Purchase venue is another important and distinguishing factor. Wang et al. (2009) reported that supermarkets are starting to provide more information on production origin, hygiene and sanitation, trying to give the best assurance for food safety.

Safety certification is one of the reliable sources for consumers when shopping food, although it was put in a lower position, it ranked higher than price. Participants were more likely to trust certifications guaranteed by the Government, followed by third-party domestic or international certifications. The importance of certifications is in agreement with results reported by Mirosa et al. (2020), who found that certifications are the most important safety cues for Chinese consumers while purchasing food. It is worth noting that the participants who had a higher education level prefer to identify the safe dairy products by certification, in line with findings by Bai et al. (2013) that highly educated consumers are more likely to value third party and industrial association certificates more than less educated persons.

\section{Conclusion}

In this study, we aimed to better understand how consumers' perceptions of food safety of dairy products and consumers' behaviour concerning dairy products, using nine focus group discussion with a total of sixty-one participants in four cities in the Northwest and South of China.

There is generally a high concern with the safety of dairy products, particularly the participants with children are more concerned about food safety and were especially worried about the safety of dairy products. Chemical residues are ranked first among concern on food safety in the dairy industry. Although Chinese consumers have a reputation for being highly price-sensitive in food purchase decisions in previous studies (Qiao et al., 2010; Xu et al., 2018; Xu et al., 2012), in our study consumers purchasing dairy products seemed to be less sensitive to price and more focused on food safety and quality.

The brand name and purchase venue were used as a cue to judge the prestige of dairy products. Participants living in the dairy-producing region have more confidence for a local brand; they prefer to choose fresher while shopping. On the contrary, participants living in the non-producing region had more positive attitudes toward the national brand over the local brand. This may imply that marketing strategies in Producing vs Non-producing regions are necessary to better meet consumers' needs and demand for dairy products.

Despite the safety certification was ranked at a relatively lower position, Chinese consumers who are more educated and affluent pay more attention to certification. This suggests that dairy enterprises may invest in implementing a brand strategy to improve consumer brand loyalty, and government or associated authorities should construct an agro-food accreditation system suitable to enable this strategy. The food traceability system can be considered an important tool for providing information to consumers (Kim and Woo, 2016; Yin et al., 2017; Canavari et al., 2010).

Despite being interesting, the findings illustrated above are qualitative and based on a small group of Chinese dairy consumers. The focus group interviews covered two regions (Northwest and South of China), but focus groups do not rely on statistical sampling and are not suitable to provide a statistically sound representation of the population. The participants come from Northwest and South of the country. Thus, the findings may not apply to other areas of the country.

However, the results can serve as input for further research. In our study, we highlighted the possible difference in attitudes between consumers in producing and non-producing regions, probably due to familiarity with the product, and considering the increasing interest in dairy production and consumption this topic is worth investigating, for instance through a nation-wide segmentation study. 
Also, the lack of mentions for nutrition as a relevant purchase factors for dairy products would require further investigation, considering the government's efforts in promoting milk consumption for health-related reasons. Starting from the relevant factors identified in this study, safety perception of dairy products should be analysed using quantitative research methods, also focusing on willingness to pay for safe, traceable and certified dairy products.

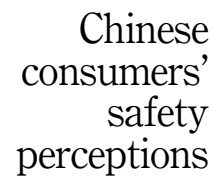

1847

\section{References}

Asioli, D., Canavari, M., Pignatti, E., Obermowe, T., Sidali, K.L., Vogt, C. and Spiller, A. (2014), "Sensory experiences and expectations of Italian and German organic consumers", Journal of International Food and Agribusiness Marketing, Vol. 26 No. 1, pp. 13-27, doi: 10.1080/08974438. 2012.755718.

Bai, J., Zhang, C. and Jiang, J. (2013), "The role of certificate issuer on consumers' willingness-to-pay for milk traceability in China", Agricultural Economics, Vol. 44 Nos 4-5, pp. 537-544, doi: 10. 1111/agec.12037.

Belk, R.W., Fischer, E. and Kozinets, R.V. (2013), Qualitative Consumer \& Marketing Research, SAGE, London.

Boncinelli, F., Dominici, A., Gerini, F. and Marone, E. (2019), "Consumers wine preferences according to purchase occasion: personal consumption and gift-giving", Food Quality and Preference, Vol. 71 March 2018, pp. 270-278, doi: 10.1016/j.foodqual.2018.07.013.

Borgogno, M., Favotto, S., Corazzin, M., Cardello, A.V. and Piasentier, E. (2015), “The role of product familiarity and consumer involvement on liking and perceptions of fresh meat", Food Quality and Preference, Vol. 44, pp. 139-147, doi: 10.1016/j.foodqual.2015.04.010.

Brucks, M., Zeithaml, V.A. and Naylor, G. (2000), "Price and brand name as indicators of quality dimensions for consumer durables", Journal of the Academy of Marketing Science, Vol. 28 No. 3, pp. 359-374, doi: 10.1177/0092070300283005.

Bruschi, V., Shershneva, K., Dolgopolova, I., Canavari, M. and Teuber, R. (2015), “Consumer perception of organic food in emerging markets: evidence from Saint Petersburg, Russia", Agribusiness, Vol. 31 No. 3, pp. 414-432, doi: 10.1002/agr.21414.

Bu, F., Zhu, D. and Wu, L. (2013), "Research on the consumers' willingness to buy traceable pork with different quality information: a case study of consumers in weifang, shandong province", Asian Agricultural Research, Vol. 5 No. 5, pp. 121-124.

Cappelli, L., D’Ascenzo, F., Natale, L., Rossetti, F., Ruggieri, R. and Vistocco, D. (2017), “Are consumers willing to pay more for a 'made in' product? An empirical investigation on 'made in Italy", Sustainability, Vol. 9 No. 4, doi: 10.3390/su9040556.

Canavari, M., Centonze, R., Hingley, M. and Spadoni, R. (2010), "Traceability as part of competitive strategy in the fruit supply chain”, British Food Journal, Vol. 112 No. 2, pp. 171-186, doi: 10. 1108/00070701011018851.

Chamhuri, N. and Batt, P.J. (2015), "Consumer perceptions of food quality in Malaysia", British Food Journal, Vol. 117 No. 3, pp. 1168-1187, doi: 10.1108/BFJ-08-2013-0235.

Chen, T., Song, M., Nanseki, T., Takeuchi, S., Zhou, H. and Li, D. (2013), "Consumer willingness to pay for food safety in Shanghai China: a case study of gap-certified milk", Journal of the Faculty of Agriculture, Kyushu University, Vol. 58 No. 2, pp. 467-473.

Cheng, L., Jiang, S., Zhang, S., You, H., Zhang, J., Zhou, Z., Xiao, Y., Liu, X., Du, Y., Li, J., Wang, X., Xin, Y., Zheng, Y. and Shang, K. (2016), "Consumers' behaviors and concerns on fresh vegetable purchase and safety in Beijing urban areas, China”, Food Control, Vol. 63, pp. 101-109, doi: 10. 1016/j.foodcont.2015.11.024.

Chocarro, R., Cortiñas, M. and Elorz, M. (2009), "The impact of product category knowledge on consumer use of extrinsic cues - a study involving agrifood products", Food Quality and Preference, Vol. 20 No. 3, pp. 176-186, doi: 10.1016/j.foodqual.2008.09.004. 
BFJ 123,5
Cui, Y., Liu, Y., Woock, P.R., Zhang, X. and Cacciolatti, L. (2016), "A qualitative exploratory investigation on the purchase intention of consumers affected by long-term negative advertising: a case from the Chinese milk sector", Economia Agro-Alimentare/Food Economy, Vol. 18 No. 3, doi: 10.3280/ECAG2016-003002.

Feng, H., Feng, J., Tian, D. and Mu, W. (2012), “Consumers' perceptions of quality and safety for grape products: a case study in Zhejiang Province, China”, British Food Journal, Vol. 114 No. 11, pp. 1587-1598, doi: 10.1108/00070701211273054.

Gao, Z., Li, C., Bai, J. and Fu, J. (2015), "Chinese consumer quality perception and preference of sustainable milk”, China Economic Review. doi: 10.1016/j.chieco.2016.05.004.

Guozheng, Z., Jueyu, W. and Fangfang, Z. (2012), “A study on Consumers' purchasing intention based on risk and product perception: a case study of dairy consumers in Changsha", Journal of Anhui Agricultural Sciences, Vol. 40 No. 36, pp. 17716-17717 + 17753, doi: 10.13989/j.cnki.05176611.2012.36.031.

Hansstein, F.V. (2015), "Consumer knowledge and attitudes towards food traceability: a comparison between the European Union, China and North America", International Proceedings of Chemical, Biological and Environmental Engineering, Vol. 51 No. 26, pp. 139-142, doi: 10.7763/ IPCBEE.

Hasimu, H., Marchesini, S. and Canavari, M. (2017), "A concept mapping study on organic food consumers in Shanghai, China”, Appetite, Vol. 108, pp. 191-202, doi: 10.1016/j.appet.2016.09.019.

Jin, S., Zhang, Y. and Xu, Y. (2017), "Amount of information and the willingness of consumers to pay for food traceability in China”, Food Control, Vol. 77, pp. 163-170, doi: 10.1016/j.foodcont.2017. 02.012 .

Kendall, H., Kuznesof, S., Dean, M., Chan, M.-Y., Clark, B., Home, R., Stolz, H., Zhong, Q., Liu, C., Brereton, P. and Frewer, L. (2018), "Chinese consumer's attitudes, perceptions and behavioural responses towards food fraud”, Food Control, Vol. 95 August 2018, pp. 339-351, doi: 10.1016/j. foodcont.2018.08.006.

Kim, Y.G. and Woo, E. (2016), "Consumer acceptance of a quick response (QR) code for the food traceability system: application of an extended technology acceptance model (TAM)", Food Research International, Vol. 85, pp. 266-272, doi: 10.1016/j.foodres.2016.05.002.

Kum, S.S., Northridge, M.E. and Metcalf, S.S. (2018), "Using focus groups to design systems science models that promote oral health equity", BMC Oral Health, Vol. 18 No. 1, pp. 1-11, doi: 10.1186/ s12903-018-0560-0.

Lam, H.-M., Remais, J., Fung, M.-C., Xu, L. and Sun, S.S.-M. (2013), "Food supply and food safety issues in China", Lancet, Vol. 381, pp. 2044-2053, doi: 10.1016/S0140-6736(13)60776-X.

Lichtman, M. (2014), Qualitative Research for the Social Sciences, SAGE Publications, London, doi: 10. 4135/9781544307756.

Lindberg, U., Salomonson, N., Sundström, M. and Wendin, K. (2018), "Consumer perception and behavior in the retail foodscape-A study of chilled groceries", Journal of Retailing and Consumer Services, Vol. 40 September, 2017, pp. 1-7, doi: 10.1016/j.jretconser.2017.09.001.

Liu, Y., Zeng, Y. and Yu, X. (2009), "Consumer willingness to pay for food safety in Beijing: a case study of food additives", The International Association of Agricultural Economists Conference, April, available at: http://ageconsearch.umn.edu/bitstream/51234/2/556-Consumer Willingness to Pay for Food Safety in Beijing-A Case Study of Food Additives.pdf.

Liu, R., Pieniak, Z. and Verbeke, W. (2014), Food-related hazards in China: consumers ' perceptions of risk and trust in information sources, Food Control, Vol. 46, pp. 291-298, doi: 10.1016/j.foodcont. 2014.05.033.

Mirosa, M., Liu, Y. and Bremer, P. (2020), “Chinese consumers ' perceptions of food safety cues and maximising the effectiveness of food safety communications", British Food Journal, Vol. 11 No. 3000030866, doi: 10.1108/BFJ-09-2019-0694. 
Onwuegbuzie, A.J., Dickinson, W.B., Leech, N.L. and Zoran, A.G. (2009), "A qualitative framework for collecting and analysing data in focus group research", International Journal of Qualitative Methods, Vol. 8 No. 3, pp. 1-21, doi: 10.1177/160940690900800301.

Peng, Y., Li, J., Xia, H., Qi, S. and Li, J. (2015), “The effects of food safety issues released by we media on consumers' awareness and purchasing behavior: a case study in China", Food Policy, Vol. 51, pp. 44-52, doi: 10.1016/j.foodpol.2014.12.010.

Qiao, G., Guo, T. and Klein, K.K. (2010), "Melamine in Chinese milk products and consumer confidence", Appetite, Vol. 55 No. 2, pp. 190-195, doi: 10.1016/j.appet.2010.05.047.

Qiao, G., Guo, T. and Klein, K.K. (2012), "Melamine and other food safety and health scares in China: Comparing households with and without young children", Food Control, Vol. 26 No. 2, pp. 378-386, doi: 10.1016/j.foodcont.2012.01.045.

Roos, G.M., Hansen, K.V. and Skuland, A.V. (2016), "Consumers, Norwegian food and belonging: a qualitative study”, British Food Journal, Vol. 118 No. 10, pp. 2359-2371, doi: 10.1108/BFJ-012016-0041.

Veeck, G., Veeck, A. and Zhao, S. (2015), "Perceptions of food safety by urban consumers in Nanjing, China”, The Professional Geographer, Vol. 67 No. 3, pp. 490-501, doi: 10.1080/00330124.2015. 1028514.

Verbeke, W., Scholderer, J. and Lähteenmäki, L. (2009), "Consumer appeal of nutrition and health claims in three existing product concepts", Appetite, Vol. 52 No. 3, pp. 684-692, doi: 10.1016/j. appet.2009.03.007.

Wang, L. and Huo, X. (2016), Willingness-to-pay price premiums for certified fruits - a case of fresh apples in China, Food Control. doi: 10.1016/j.foodcont.2016.01.005.

Wang, Z., Mao, Y. and Gale, F. (2008), "Chinese consumer demand for food safety attributes in milk products”, Food Policy, Vol. 33 No. 1, pp. 27-36, doi: 10.1016/j.foodpol.2007.05.006.

Wang, F., Zhang, J., Mu, W., Fu, Z. and Zhang, X. (2009), “Consumers' perception toward quality and safety of fishery products, Beijing, China”, Food Control, Vol. 20 No. 10, pp. 918-922, doi: 10. 1016/j.foodcont.2009.01.008.

Ward, M. and Inouye, A. (2018), China - Peoples Republic of Dairy and Products Semi-annual Fluid Milk Consumption Continues to Increase, United States Department of Agriculture, Washington, DC, available at: https://apps.fas.usda.gov/newgainapi/api/report/downloadreportbyfilename? filename $=$ Dairy $\% 20$ and $\% 20$ Products $\% 20$ Semi-annual_Beijing_China $\% 20-\% 20$ Peoples $\%$ 20Republic\%20of_5-16-2018.pdf.

Williams, E., Stewart-Knox, B. and Rowland, I. (2005), "A qualitative analysis of consumer perceptions of mood, food and mood-enhancing functional foods", Journal of Nutraceuticals, Functional and Medical Foods, Vol. 4 Nos 3-4, pp. 61-83, doi: 10.1300/J133v04n03_05.

Wu, L., Zhong, Y., Shan, L. and Qin, W. (2013), "Public risk perception of food additives and food scares. the case in Suzhou, China”, Appetite, Vol. 70, pp. 90-98, doi: 10.1016/j.appet.2013.06.091.

Wu, X., Lu, Y., Xu, H., Lv, M., Hu, D., He, Z., Liu, L., Wang, Z. and Feng, Y. (2018), “Challenges to improve the safety of dairy products in China", Trends in Food Science and Technology, Vol. 76 February, pp. 6-14, doi: 10.1016/j.tifs.2018.03.019.

$\mathrm{Xu}, \mathrm{P}$., Zheng, S. and Motamed, M. (2010), "Perceived risks and safety concerns about fluid milk among Chinese college students", Agricultural Economics, Vol. 56 No. 2, pp. 67-78, doi: 10.17221/ 18/2009-AGRICECON.

Xu, P., Zeng, Y., Fong, Q., Lone, T. and Liu, Y. (2012), “Chinese consumers' willingness to pay for green- and eco-labeled seafood", Food Control, Vol. 28 No. 1, pp. 74-82, doi: 10.1016/j.foodcont. 2012.04.008.

$\mathrm{Xu}, \mathrm{P} ., \mathrm{Su}, \mathrm{H}$. and Lone, T. (2018), “Chinese consumers' willingness to pay for rice”, Journal of Agribusiness in Developing and Emerging Economies, Vol. 8 No. 2, pp. 256-269, doi: 10.1108/ JADEE-11-2016-0077. 
$\mathrm{BFJ}$ 123,5
Yin, S., Li, Y., Xu, Y., Chen, M. and Wang, Y. (2017), "Consumer preference and willingness to pay for the traceability information attribute of infant milk formula: evidence from a choice experiment in China”, British Food Journal, Vol. 119 No. 6, pp. 1276-1288, doi: 10.1108/BFJ-11-2016-0555.

Zamawe, F.C. (2015), "The implication of using NVivo software in qualitative data Analysis : evidencebased reflections", Malawi Medical Journal, Vol. 27 April, pp. 8-11, doi: 10.4314/mmj.v27i1.4.

Zeng, L., Zhou, L., Pan, P.-L. and Fowler, G. (2018), "Coping with the milk scandal:A staged approach to crisis communication strategies during China's largest food safety crisis", Journal of Communication Management, Vol. 22 No. 4, pp. 432-450, doi: 10.1108/JCOM-11-2017-0133.

Zhang, C., Bai, J., Lohmar, B.T. and Huang, J. (2010), "How do consumers determine the safety of milk in Beijing, China?", China Economic Review, Vol. 21 SUPPL. 1, pp. S45-S54, doi: 10.1016/j.chieco. 2010.05.008.

Zhu, L. and Xu, Y. (2017), "The study of consumers paid a premium for the food quality information label-taking infant formula as an example", Price:Theory and Practice, Vol. 11, pp. 146-149.

Zhu, X., Yuelu Huang, I. and Manning, L. (2019), "The role of media reporting in food safety governance in China: a dairy case study", Food Control, Vol. 96 June 2018, pp. 165-179, doi: 10. 1016/j.foodcont.2018.08.027.

Zingg, A., Cousin, M.-E., Connor, M. and Siegrist, M. (2013), "Public risk perception in the total meat supply chain", Journal of Risk Research, Vol. 16 No. 8, pp. 1005-1020, doi: 10.1080/13669877. 2013.788057.

\section{Corresponding author}

Maurizio Canavari can be contacted at: maurizio.canavari@unibo.it 
Appendix

Chinese

consumers'

safety

perceptions

Themes of discussion
Consumers' food safety
perception

Northwest

"Food safety issue is my topic concern; it is also what worries me most because I have a baby so I more concerned and more worried about the dairy products' safety. I feel the dairy product that is produced in Xinjiang is safer, because I think the origin of the dairy product is very important, and the animal husbandry has been the traditional and basic industry in Xinjiang, the products that are produced there should be fine. Another important reason is I haven't heard about safety incidents with dairy products which produced in Xinjiang" (G3, male, 30) "Xinjiang is a livestock breeding area, and I think the source of dairy products is safe. Otherwise, my relative or I also have not any experience with dairy products, so I think the dairy products are safe in Xinjiang" (G1, female, 21 age)

"I think the food safety situation is not very well now, more food safety accidents have occurred in the recent year, was very worrying, besides there are two elderly people (over 60) in my family, I am more concerned and worried about food safety" (G5, male, 30)

The Aspects of consumers' concern about dairy products

The Influence of social media on consumers' perception
"I am concerned about chemical residues in food; there are potential chemical contaminants including heavy metals, residual pesticides that can be found in during the process of manufacture, storing, transporting and selling. Although will be cleaned and sterilised, no guarantee" (G1, female, 23) "I bought expired milk product before, but I did not know that the product has already expired. ....so now I will pay more attention when I buy foods" (G4, female, 42)
South

"Although the food safety situation is not as bad now, I am still worried about food safety, especially the safety of dairy products" (G7, male, 40)
"I am afraid to buy counterfeit and shoddy products, especially worry about buying expired milk" (G6, female, 22)

"I think food safety situation of dairy products is currently not bad, but after all, had been occurred very serious food safety incidents like Sanlu melamine incident ... it is terrifying ... so I cannot feel quite at ease about food safety ... I think the government should continue to increase investment and supervision on food quality control". (G6,male, 20)
Table A1.

Discussion in the Northwest and South

(continued) 


\section{$\mathrm{BFJ}$ 123,5}

1852

Themes of discussion
Consumers' concerns
while purchasing dairy
products

products

How do consumers determine the safety of dairy products?
Table A1.

Northwest South

"Freshness is very important for a dairy product, I looked at the expiration date in order to know whether the product is fresh, I also looked at the information about quality if it had, and I just hope to buy a safe food" (G4, female, 50)

"I mainly pay attention to freshness; firstly I would to look at the production date and pick up newest product to buy. For several years, I have always bought just one brand's products, so I just need to consider freshness" (G1, female, 23)

"Except the freshness, I will consider on the brand of dairy products while buying, and I trust the quality of foods which is produced by a big company" (G1, male, 23)

"For several years, I have been consuming the Xi Yuchun products (local dairy enterprises of Xinjiang), there have been no food safety accidents with this brand, additionally, they are the member of "school milk program", I trust this brand, so will pay more attention on the brand when I'm buying" (G1, female, 23)"

"I would like to buy dairy products in supermarkets like Carrefour,

Friendship Supermarket, Wal-Mart ... . and so on; I think retailers should be responsible for the quality of foods that they sell, so I think the foods which are sold in big supermarkets are safer" (G1, male, 23)

"I usually buy the dairy products in the store near my home; I will often buy at there, I fell the foods include dairy products are safe in there, at the same time I will notice the certification information of products" (G3, female, 21) "I have more trust in safety certification rather than brand because certified food adopts a third-party certification that means it meets some kind of quality standard. In the other way, some well-known brand has also had a problem with foods safety, for instance, Sanlu Milk" (G1, female, 23)
"I often buy milk powder for our baby, and I pay more attention to the safety of dairy products" (G9, male, 35)

"In previous years, reports about food safety incidents, such as the "Sanlu milk powder incident. . .had often been seen in the media so that I will pay more attention to the brand of the company, particularly a dairy company... because there is a child in my family, I am afraid to buy poor quality foods ...”. (G9 female, 34)

"I believe that the dairy producers should guarantee the quality of its foods and services, be responsible to consumers, I pay more attention to the brand of dairy product, if the brand is credible and reliable, the food is safer certainly" (G8 female, 32) 